\title{
Risk Assessment of Heavy Metals in Chromolaena odorata Collected Around Gemstone Mining Site in Ijero-Ekiti
}

\author{
Efe Sylvanus Abiya, Foluso Akinbode Ologundudu*, Ekpo Wisdom \\ Department of Biology, Federal University of Technology Akure, Nigeria. \\ Corresponding author* \\ akinbodefoluso@gmail.com
}

Manuscript received: 27 July 2021. Revision accepted: 02 August, 2021. Published: 01 October, 2021.

\begin{abstract}
In Nigeria, like many developing nations, the resultant effect of land degradation: aggravated soil erosion, flood disasters, salinization or alkalisation, and the desertification have been a major public health concern for the past decades, however this study highlighted some of the factors that leads to the menace of soil fertility. The study was conducted at a gemstone mining site in Ijero Ekiti, Ekiti State, Nigeria. The soil samples were collected at a depth of $0-15 \mathrm{~cm}$ top soil and $0-30 \mathrm{~cm}$ subsoil. A line transect of $20 \mathrm{~cm}$ was drawn and soil sample was collected, all samples were kept in a clean container and labeled accordingly before been transported to the laboratory for analysis. The plant samples were thoroughly washed with distilled water to remove dust and other particles, air dried in a dust free wire meshed cage. All data obtained from this research were subjected to one-way analysis of variance (ANOVA). The result obtained in this study indicated that the levels of heavy metal concentration tested were still within the permissible limit in the root and shoot of Chromolaena odorata between the mine and control site. The implication of this is that Chromolaena odorata is safe for human and animal consumption. The said plant can readily undergo photosynthetic activity to aid growth by exploiting the presence of these metals either as a macro-nutrient or micro-nutrient as seen from the Translocation Factor and Metal Transfer Factor. The study concludes that soil at IjeroEkiti mine site were slightly acidic soil $\mathrm{pH}$, reduced organic carbon, total nitrogen, available phosphorus, exchangeable cations and averagely elevated heavy metal contents.
\end{abstract}

Keywords: Chromonlaena odorata; Gemstone; Permissible limit; Photosynthetic ability; Transfer factor; heavy metal.

\section{INTRODUCTION}

Major problem of land degradation and pollution arise as a result of exploitation and excavation of the natural environment with an increase in sophisticated tools and methods and also revolution in industrialization in large scale pose a serious threat to the world's resources and environmental degradation with socio-economic impacts Katar (2009). The main causes of this degradation are transformation of fertile cultivated land into wasteland and in some cases pose serious environmental pollution and ecological degradation which can leads to loss of biodiversity (Keskin and Makineci, 2009). Mining is one of the major factors that have pose serious threat and hazards that can jeopardize ecosystems of nations. Nigeria has been actively engaged in solid mineral exploitation for more than decades and endowed with deposit of more than 34 solid minerals including coal, tin, gold and many more across the country. Adekoya et al., 2003, southwestern part of the country has about $25 \%$ of the total land mass consisting of sedimentary rocks and hence mining activities are common. Mining operations alter a site's ecosystem by disrupting the ecological balance, landscapes, agricultural lands, forests, plantations and vegetation as well as the economic food and tree crops. Other impacts of mining include alteration of the soil structure, loss and overturning of the fertile top soil, air, soil and water pollution, instability of soil and rock masses, destruction of flora and fauna, casing mass exodus of species of animals (Adegboye, 2012). However, the health implications associated to mining as recorded by Kitula (2004) in Tanzania that the symptoms of heavy metals poisoning such as sensory disturbance, metallic taste and night blindness are common and also the world health organizations reported the prevalence of human diseases during the past decade is rapidly increasing due to effect of heavy metals.

\section{METHODS}

\section{Study area}

The study was conducted at a gemstone mining site in Ijero Ekiti, Ekiti State, South western region of Nigeria.

\section{Sample collection}

Soil and plants samples were collected at the different spots at the gemstone mining site in Ijero Ekiti, Ekiti State. The soil samples were collected at a depth of 0-15 
$\mathrm{cm}$ top soil and 0-30 cm subsoil. A line transect of 20 $\mathrm{cm}$ was drawn and soil sample was collected, all samples were kept in a clean container and labeled accordingly before been transported to the laboratory for analysis. The plant samples were thoroughly washed with distilled water to remove dust and other particles, then air dried in a dust free wire meshed cage. The analysis was carried out at the Sustainable Environmental Laboratory and Crop, Soil and Pest Management in Federal University of Technology Akure.

\section{Soil physico-chemical properties, $\mathrm{Ph}$ and conductivity of soil}

Ten gram of the soil sample was weighed and placed into a sample cup; $20 \mathrm{ml}$ of water was measured and poured into it. Setup was allowed to stand for 30 minutes. Afterwards, the $\mathrm{pH}$ meter was inserted into the dissolved soil sample and the reading was taken. At a room temperature of $28^{\circ} \mathrm{C}$, soil conductivity was conducted using the auto-conductivity machine and the reading were recorded.

\section{Organic carbon and organic matter}

Little of the soil sample was pulverized. 1 gram was weighed into a $250 \mathrm{ml}$ conical flask. $10 \mathrm{ml}$ of potassium dichromate $\left(\mathrm{K}_{2} \mathrm{Cr}_{2} \mathrm{O}_{7}\right)$ was added. $20 \mathrm{ml}$ of sulphuric acid $\left(\mathrm{H}_{2} \mathrm{SO}_{4}\right)$ was further added and the flask was swirl vigorously for one minute. Afterwards, $100 \mathrm{ml}$ of distilled water was added after standing for 30minutes. 3-4 drops of ferroin indicator and titrate with $0.5 \mathrm{M}$ Iron (II) ammonium sulphate $\left(\mathrm{Fe}_{2} \mathrm{NH}_{4} \mathrm{SO}_{2}\right)$, takes a greenish cast and then changes to dark green. At this point, ferrous sulphate was added drop by drop until colour change was observed from green to brownish red.

\section{Metal analysis}

About 1.0 to 2.0 gram of the sample was weighed into a $250 \mathrm{ml}$ conical flask after dried in an oven for one hour. $20 \mathrm{ml}$ of Trioxonitrate acid $\left(\mathrm{HNO}_{3}\right)$ was added. Then it was heated in a heater starting with low temperature for about 15 to 20 minutes. The heat was increased to medium temperature for about 30 minutes again and finally at high heating until complete digestion is required. The flask was rotated at intervals until the digest is clear (white fumes) continue heating for few minutes after that to ascertain complete digestion, that is, a clear solution is an evidence of complete a complete digestion. After cooling the sample residue was filtered and use to make up the digest up to 50 or $100 \mathrm{ml}$ or as appropriate. After being placed in a sample bottle the concentration using Atomic Absorption Spectrophotometer (AAS) or flame photometer was carried out for the elements like ( $\mathrm{Ni}, \mathrm{Cd}, \mathrm{As}, \mathrm{Cu}, \mathrm{Zn}, \mathrm{Pb}$ and $\mathrm{Cr}$ ). Most importantly, the machine (AAS) must be powered for about 30 to 45 minutes before introducing any sample into it. This is done to increase the efficiency of the machine.

\section{Statistical analysis}

All data obtained from this research were subjected to one-way Analysis of Variance (ANOVA) and means separated with new Duncan's multiple range tests using SPSS 17.0 version of Windows 7 statistical package was used.

\section{RESULTS}

Table 1. Soil textural class of the soil samples.

\begin{tabular}{|c|c|c|c|c|}
\hline Soil Samples & $\begin{array}{l}\% \\
\text { Clay }\end{array}$ & $\begin{array}{l}\% \\
\text { Silt }\end{array}$ & $\begin{array}{l}\% \\
\text { Sand }\end{array}$ & $\begin{array}{l}\text { Soil Textural } \\
\text { Class }\end{array}$ \\
\hline Transect site & 30.48 & 15.28 & 54.2 & Sandy clay \\
\hline Mining site & 30.48 & 15.28 & 54.28 & Sandy clay \\
\hline Control site & 26.48 & 9.28 & 64.2 & Sandy laomy \\
\hline
\end{tabular}

Physico-chemical characteristics of soil at the mining and control sites.

Table 2 shows the physical and chemical (physicochemical) characteristics of soil sampled at the mine and control sites. The $\mathrm{pH}$ value at the mining site $(6.81 \pm$ $0.01)$ is slightly elevated compared to the control site $(6.51 \pm 0.01)$ and are significantly different from each other $(\mathrm{p}<0.05)$. Generally, elevated levels of concentration were observed for conductivity, bulk density, phosphorus, exchangeable cation ( $\mathrm{Mg}, \mathrm{K}, \mathrm{Na}$, $\mathrm{Ca})$, Cation exchange capacity, organic carbon and total nitrogen between soils of mine site and control site respectively which are also not significantly different $(\mathrm{p}$ $<0.05)$.

Table 2. Physico-chemical characteristics of soil at the mining and control sites.

\begin{tabular}{|c|c|c|c|c|c|c|c|}
\hline Soil Parameters & Pair & Mean \pm S.E & $\mathbf{N}$ & S.D & t. cal & Sig & Remarks \\
\hline \multirow[t]{2}{*}{$\mathrm{pH}$} & $\mathrm{M}$ & $6.51 \pm 0.01$ & 3 & 0.01 & 36.742 & 0.001 & $\mathrm{~S}$ \\
\hline & $\mathrm{C}$ & $6.81 \pm 0.01$ & 3 & 0.01 & & & \\
\hline \multirow[t]{2}{*}{ Conductivity } & M & $644.3 \pm 0.88$ & 3 & 1.53 & 378.976 & 0.000 & NS \\
\hline & $\mathrm{C}$ & $171.6 \pm 0.88$ & 3 & 1.53 & & & \\
\hline \multirow[t]{2}{*}{ Porosity } & M & $47.2 \pm 0.57$ & 3 & 1.00 & -7.232 & 0.005 & NS \\
\hline & $\mathrm{C}$ & $51.9 \pm 0.32$ & 3 & 0.55 & & & \\
\hline Bulk Density & M & $1.32 \pm 0.01$ & 3 & 0.01 & 12.017 & 0.001 & NS \\
\hline
\end{tabular}




\begin{tabular}{|c|c|c|c|c|c|c|c|}
\hline Soil Parameters & Pair & Mean \pm S.E & $\mathbf{N}$ & S.D & t. cal & Sig & Remarks \\
\hline & $\mathrm{C}$ & $1.19 \pm 0.01$ & 3 & 0.02 & & & \\
\hline \multirow[t]{2}{*}{ Sodium } & M & $2.52 \pm 0.01$ & 3 & 0.02 & -70.835 & 0.000 & NS \\
\hline & $\mathrm{C}$ & $1.77 \pm 0.01$ & 3 & 0.01 & & & \\
\hline \multirow[t]{2}{*}{ Phosphorus } & M & $4.66 \pm 0.01$ & 3 & 0.02 & -231.715 & 0.001 & NS \\
\hline & $\mathrm{C}$ & $7.55 \pm 0.01$ & 3 & 0.02 & & & \\
\hline \multirow[t]{2}{*}{ Potassium } & M & $5.21 \pm 0.01$ & 3 & 0.01 & 4.000 & 0.000 & NS \\
\hline & $\mathrm{C}$ & $7.46 \pm 0.01$ & 3 & 0.01 & & & \\
\hline \multirow[t]{2}{*}{ Calcium } & M & $1.59 \pm 0.01$ & 3 & 0.02 & 32.571 & 0.000 & NS \\
\hline & $\mathrm{C}$ & $1.25 \pm 0.01$ & 3 & 0.01 & & & \\
\hline \multirow[t]{2}{*}{ Magnesium } & M & $1.91 \pm 0.01$ & 3 & 0.01 & 39.528 & 0.000 & NS \\
\hline & $\mathrm{C}$ & $1.49 \pm 0.01$ & 3 & 0.02 & & & \\
\hline \multirow[t]{2}{*}{ CEC } & M & $3.17 \pm 0.01$ & 3 & 0.01 & 86.963 & 0.000 & NS \\
\hline & $\mathrm{C}$ & $2.25 \pm 0.01$ & 3 & 0.02 & & & \\
\hline \multirow[t]{2}{*}{ Org. Carbon } & M & $0.94 \pm 0.01$ & 3 & 0.01 & -53.889 & 0.001 & NS \\
\hline & $\mathrm{C}$ & $1.38 \pm 0.01$ & 3 & 0.01 & & & \\
\hline \multirow[t]{2}{*}{ Nitrogen } & M & $0.85 \pm 0.01$ & 3 & 0.01 & -52.664 & 0.00 & NS \\
\hline & $\mathrm{C}$ & $1.28 \pm 0.01$ & 3 & 0.01 & & & \\
\hline
\end{tabular}

Note: S - Significant; NS - Not Significant; M - Mining; C - Control; S.D - Standard deviation; t.cal/t-calculated; S.E-Standard Error; $\mathrm{N}$ - Number of replicates

\section{Physical and Chemical characteristics of soil at the line transect and control sites.}

Table 3 shows the physical and chemical (physicochemical) characteristics of soil samples at the line transect site and control sites. The $\mathrm{pH}$ value at the line transect site $(6.99 \pm 0.01)$ is slightly elevated compared to the control $(6.51 \pm 0.01)$ site and are not significantly different to each other $(\mathrm{p}<0.05)$. Generally, there are no significant differences observed for the concentration of conductivity, bulk density, organic carbon, phosphorus, exchangeable cation $(\mathrm{Mg}, \mathrm{K}, \mathrm{Na}, \mathrm{Ca})$ and total nitrogen between soils of the line transect site and control site and are also not significantly different $(\mathrm{p}<0.05)$ from each other.

Table 3. Physico-chemical characteristics of soil at the line transect and control sites.

\begin{tabular}{|c|c|c|c|c|c|c|c|}
\hline Soil Parameters & PAIR & MEAN \pm S.E & $\mathbf{N}$ & S.D & t.cal & Sig & Remarks \\
\hline \multirow[t]{2}{*}{ pH } & $\mathrm{T}$ & $6.99 \pm 0.01$ & 3 & 0.01 & 58.788 & 0.000 & $\mathrm{NS}$ \\
\hline & $\mathrm{C}$ & $6.51 \pm 0.01$ & 3 & 0.01 & & & \\
\hline \multirow[t]{2}{*}{ Conductivity } & $\mathrm{T}$ & $364.0 \pm 0.57$ & 3 & 1.00 & 182.463 & 0.000 & NS \\
\hline & $\mathrm{C}$ & $171.6 \pm 0.88$ & 3 & 1.52 & & & \\
\hline \multirow[t]{2}{*}{ Porosity } & $\mathrm{T}$ & $45.5 \pm 0.57$ & 3 & 0.01 & -9.697 & 0.001 & $\mathrm{~S}$ \\
\hline & $\mathrm{C}$ & $51.9 \pm 0.32$ & 3 & 0.55 & & & \\
\hline \multirow[t]{2}{*}{ Bulk Density } & $\mathrm{T}$ & $1.35 \pm 0.01$ & 3 & 0.02 & 12.829 & 0.000 & NS \\
\hline & $\mathrm{C}$ & $1.19 \pm 0.01$ & 3 & 0.02 & & & \\
\hline \multirow{2}{*}{ Sodium } & $\mathrm{T}$ & $3.43 \pm 0.01$ & 3 & 0.01 & 111.452 & 0.000 & NS \\
\hline & $\mathrm{C}$ & $2.52 \pm 0.01$ & 3 & 0.01 & & & \\
\hline \multirow[t]{2}{*}{ Phosphorus } & $\mathrm{T}$ & $14.6 \pm 0.01$ & 3 & 0.02 & 570.870 & 0.000 & NS \\
\hline & $\mathrm{C}$ & $7.55 \pm 0.01$ & 3 & 0.02 & & & \\
\hline \multirow[t]{2}{*}{ Potassium } & $\mathrm{T}$ & $8.82 \pm 0.01$ & 3 & 0.01 & 166.565 & 0.001 & NS \\
\hline & $\mathrm{C}$ & $7.46 \pm 0.01$ & 3 & 0.01 & & & \\
\hline \multirow[t]{2}{*}{ Calcium } & $\mathrm{T}$ & $1.49 \pm 0.01$ & 3 & 0.02 & 23.085 & 0.000 & NS \\
\hline & $\mathrm{C}$ & $1.25 \pm 0.01$ & 3 & 0.01 & & & \\
\hline \multirow[t]{2}{*}{ Magnesium } & $\mathrm{T}$ & $2.11 \pm 0.01$ & 3 & 0.01 & 58.502 & 0.001 & NS \\
\hline & $\mathrm{C}$ & $1.49 \pm 0.01$ & 3 & 0.02 & & & \\
\hline \multirow[t]{2}{*}{ CEC } & $\mathrm{T}$ & $4.12 \pm 0.01$ & 3 & 0.01 & 177.088 & 0.001 & NS \\
\hline & $\mathrm{C}$ & $2.25 \pm 0.01$ & 3 & 0.02 & & & \\
\hline \multirow[t]{2}{*}{ Org. Carbon } & $\mathrm{T}$ & $1.95 \pm 0.01$ & 3 & 0.02 & 54.391 & 0.000 & NS \\
\hline & $\mathrm{C}$ & $1.38 \pm 0.01$ & 3 & 0.01 & & & \\
\hline \multirow[t]{2}{*}{ Nitrogen } & $\mathrm{T}$ & $1.38 \pm 0.01$ & 3 & 0.01 & -37.967 & 0.001 & NS \\
\hline & $\mathrm{C}$ & $0.97 \pm 0.01$ & 3 & 0.01 & & & \\
\hline
\end{tabular}

Note: S - Significant; NS - Not Significant; T - Transect; C - Control; S.D - Standard deviation; t.cal/t-calculated; S.E-Standard Error; $\mathrm{N}$ - Number of replicates.

The nutrient of Zinc ( $\mathrm{Zn})$, Copper $(\mathrm{Cu})$, Cadmium $(\mathrm{Cd})$, Chromium $(\mathrm{Cr})$, Nickel $(\mathrm{Ni})$ and Lead $(\mathrm{Pb})$ in the soil at the mine site are slightly higher in abundance compared to the control site. Paradoxically, Arsenic (As) seems to have a low nutrient concentration in the soils at the mining and control sites. 
Table 4 Translocation factor of each element at the mining and control site for Chromolaena odorata

\begin{tabular}{lll}
\hline Elements & Mining Site & Control Site \\
\hline $\operatorname{Tf}(\mathrm{Cu})$ & 0.796 & 0.456 \\
$\mathrm{Tf}(\mathrm{Zn})$ & 0.982 & 0.853 \\
$\mathrm{Tf}(\mathrm{Pb})$ & 0.939 & 0.876 \\
$\mathrm{Tf}(\mathrm{Ni})$ & 0.759 & 0.704 \\
$\mathrm{Tf}(\mathrm{As})$ & 0.001 & 0.001 \\
$\mathrm{Tf}(\mathrm{Cr})$ & 0.953 & 0.014 \\
Tf $(\mathrm{Cd})$ & 0.800 & 0.333 \\
\hline
\end{tabular}

Note: Tf - Translocation factor.

Translocation factor $(\mathrm{Tf})=$

Concentration of metals $(\mathrm{Mg} / \mathrm{kg})$ in the receiving level (shoot)

Concentration of metals $(\mathrm{Mg} / \mathrm{kg}$ ) in the source level (root)

Translocation factor of each element between the soils at the mining and control sites in tree herb

The nutrient of Copper $(\mathrm{Cu})$, Zinc $(\mathrm{Zn})$, Lead $(\mathrm{Pb})$ and Cadmium $(\mathrm{Cd})$ in the soil at the mine site are considerably higher in abundance compared to the control site. In contrast, Nickel (Ni), Arsenic (As) and Chromium $(\mathrm{Cr})$ seems to have a low nutrient in soil at the mine and control site.

Table 5 Translocation factor of each element both at the mining and control site for the tree herb.

\begin{tabular}{lll}
\hline Elements & Mining Site & Control Site \\
\hline Tf $(\mathbf{C u})$ & 1.224 & 0.589 \\
Tf $(\mathbf{Z n})$ & 1.176 & 0.902 \\
Tf $(\mathbf{P b})$ & 1.040 & 0.759 \\
Tf $(\mathbf{N i})$ & 0.590 & 1.516 \\
Tf $(\mathbf{A s})$ & 0.500 & 0.500 \\
Tf $(\mathbf{C r})$ & 0.956 & 0.936 \\
Tf $(\mathbf{C d})$ & 1.000 & 0.400 \\
\hline
\end{tabular}

$\mathrm{Tf}-$ Translocation factor.

Translocation factor $(T f)=$

Concentration of metals $(\mathrm{Mg} / \mathrm{kg})$ in the receiving level (shoot) Concentration of metals $(\mathrm{Mg} / \mathrm{kg}$ ) in the source level (root)

Metal transfer factor of each element between the soils at the mining and control sites in Chromolaena Odorata

The metal transfer factor of Copper $(\mathrm{Cu})$, Zinc $(\mathrm{Zn})$, Lead $(\mathrm{Pb})$ and Chromium $(\mathrm{Cr})$ seems to have a high transfer factor in the soils at the mine and control site. In contrast, Arsenic (As) and Nickel (Ni) seems to have a low metal transfer at the mine and control site respectively.

Table 6 Indication of the values of the Metal Transfer Factor of each element both at the Mining and Control site for Chromolaena odorata.

\begin{tabular}{lll}
\hline Elements & Mining Site & Control Site \\
\hline MTf $(\mathbf{C u})$ & 2.640 & 1.666 \\
MTf $(\mathbf{Z n )}$ & 3.761 & 3.130 \\
MTf $($ Pb) & 9.818 & 9.636 \\
MTf $(\mathbf{N i})$ & 0.000 & 0.000 \\
MTf $(\mathbf{A s})$ & 5.000 & 3.000 \\
MTf $(\mathbf{C r})$ & 13.700 & 10.200 \\
MTf $(\mathbf{C d})$ & 0.000 & 0.00 \\
\hline MTf - Metal transfer factor &
\end{tabular}

\author{
Metal Transfer Factor $=$ \\ $\underline{\mathrm{Mp}}=$ Metal content in plant shoot $(\mathrm{Mg} / \mathrm{kg})$ \\ $\mathrm{Ms}=$ Metal content in Soil $(\mathrm{Mg} / \mathrm{kg})$
}

Metal transfer factor of each element between the soils at the mining and control sites in tree herb

Table 7 Metal transfer factor of each element both at the mining and control site for the tree herb.

\begin{tabular}{lll}
\hline Elements & Mining Site & Control Site \\
\hline MTf $(\mathrm{Cu})$ & 6.800 & 2.813 \\
MTf $(\mathrm{Zn})$ & 4.500 & 2.488 \\
MTf $(\mathrm{Pb})$ & 6.818 & 6.000 \\
MTf $(\mathrm{Ni})$ & 0.000 & 0.000 \\
MTf $(\mathrm{As})$ & 3.000 & 1.000 \\
MTf $(\mathrm{Cr})$ & 11.800 & 11.000 \\
MTf $(\mathrm{Cd})$ & 0.000 & 0.000 \\
\hline
\end{tabular}

MTf - Metal transfer factor.

$$
\begin{gathered}
\text { Metal Transfer Factor }= \\
\frac{\mathrm{Mp}=\mathrm{Metal} \text { content in plant shoot }(\mathrm{Mg} / \mathrm{kg})}{\mathrm{Ms}=\text { Metal content in soil }(\mathrm{Mg} / \mathrm{kg})}
\end{gathered}
$$

\section{DISCUSSION}

International organizations such as United State Environmental Protection Agency (USEPA), World Health Organization (WHO) has given some guidelines for the presence of heavy metals in plant and soil (Marcovecchio et al; (2007). Therefore, heavy metals like Copper $(\mathrm{Cu})$, Zinc $(\mathrm{Zn})$, Lead $(\mathrm{Pb})$, Nickel $(\mathrm{Ni})$, Arsenic (As), Chromium (Cr) and Cadmium (Cd) has their respective permissible limit in plant and soil as specified by (WHO). The maximum permissible level in plant for $(\mathrm{Cd})$ is $0.02 \mathrm{mg} / \mathrm{kg}$; $(\mathrm{Zn})$ is $50 \mathrm{mg} / \mathrm{kg}$; $(\mathrm{Cu})$ is $10 \mathrm{mg} / \mathrm{kg}$; ( $\mathrm{Pb}$ ) is $2 \mathrm{mg} / \mathrm{kg}$; (Ni) is $10 \mathrm{mg} / \mathrm{kg}$; $(\mathrm{Cr})$ is $0.03 \mathrm{mg} / \mathrm{kg}$ and Arsenic (As) is $0.05 \mathrm{mg} / \mathrm{kg}$. The maximum permissible limit in soil for $(\mathrm{Cd})$ is $45.00 \mathrm{mg} / \mathrm{kg}$; $(\mathrm{Cu})$ is $30.00 \mathrm{mg} / \mathrm{kg}$; $(\mathrm{Pb})$ is $35.00 \mathrm{mg} / \mathrm{kg}$; (Ni) is $20.00 \mathrm{mg} / \mathrm{kg}$; $(\mathrm{Cr})$ is $30.00 \mathrm{mg} / \mathrm{kg}$ and Arsenic (As) is $20.00 \mathrm{mg} / \mathrm{kg}$.

The result for heavy metals in plant in this study indicated that the levels of heavy metal concentration tested were still within the permissible limit in the root and shoot of Chromolaena odorata between the mine and control site. The implication of this is that Chromolaena odorata is safe for human and animal consumption; the said plant can readily undergo photosynthetic activity to aid growth by exploiting the presence of this metals either as a macro-nutrient or micro-nutrient as seen from the Translocation Factor (Tables 3 and 4) and Metal Transfer Factor (Table 5) calculated independently for each of the metals (Mysliwa-Kurdziel et al; (2004). However, the result also shows that the level of heavy metal concentration is significantly higher at the mine site compared to the control site. This is so because as distance from the point source increases, the concentration or toxicity level 
decreases considerably (Olafisoye et al; (2013). Another distinction observed is that $\mathrm{Zn}, \mathrm{As}$, and $\mathrm{Cd}$ are significantly different from each other (both in the root and shoot) of the aforementioned plant. This can also be due to the rate of absorption or uptake experienced between the mine and control site considerably (Yang et al., (1998) which characteristically influenced the soil type of the mine site (Sandy-Clay) and the control site (Sandy-Loam) (Table 1). Similar result was also noted for in the root and shoot of the tree herb collected at the same site. The heavy metal concentrations tested were also within permissible limit. Heavy metal pollution of soil is regarded as one of the severe environmental challenges in many countries of the world (Facchinelli et al., (2001). Concentrations of $\mathrm{Cu}, \mathrm{Zn}, \mathrm{As}, \mathrm{Cd}, \mathrm{Ni}$ and $\mathrm{Pb}$ in the soil are among the heavy metals investigated for in the mine and control site. Concentration Zinc $(\mathrm{Zn})$, Copper $(\mathrm{Cu})$, Lead $(\mathrm{Pb})$ were significantly higher at the Mining site compared to the control site although it is within the permissible limit. A previous study also showed that mining around Kabwe was responsible for heavy metal pollution, especially by $\mathrm{Pb}$ (Tembo et al., (2006). That paper indicated that the heavy metal concentrations decreased with increasing distance from the mine, confirming that mining activities are the main cause of soil contamination. Lead $(\mathrm{Pb})$ toxicity causes many diseases including hematological, gastrointestinal and neurological dysfunctions, and nephropathy (Lockitch,1993). It is reported that children have a greater susceptibility to $\mathrm{Pb}$ toxicity because intestinal absorption of $\mathrm{Pb}$ is five times greater in children than in adults. Oelofse (2008) also reported elevated concentrations of $\mathrm{As}, \mathrm{Cu}, \mathrm{Cd}$ and $\mathrm{Pb}$ at the Ijero-Ekiti mine soil. Cooke and Johnson (2002), Akcil and Koldas (2006) and Arogunjo (2007) observed that low pH in mine soils promoted solubility of heavy metals. The slightly acidic soil pH at Ijero-Ekiti mine site is due to manual technologies adopted which resulted in the overturning of the top soil. While concentrations of heavy metals in the mine soils were slightly elevated, plant nutrient concentrations were lower at the line transect and mining site respectively (Table 6 and 7). Low levels of conductivity, bulk density, organic carbon, phosphorus, exchangeable cation

$(\mathrm{Mg}, \mathrm{K}, \mathrm{Na}, \mathrm{Ca})$ and total nitrogen were reported between soils of the line transect and mine site, and high $\mathrm{Zn}$ and $\mathrm{Cu}$ concentration occurred in the mine and transect sites, as supported by Martinez and Motto (2000) and Oelofse (2008), that mining activities negatively affected the mineralization, absorption and uptake of nutrients by the root and shoot of plant.

\section{CONCLUSION}

The primary target for the toxicity of heavy metals is still not clear yet. However, this study has showed the impact of mining activities on the plant and soil. It has provided up-to date empirical data on the current state of soil and plant degradation as a result of exploitation of solid mineral in Ijero-Ekiti Southwestern Nigeria. The study concludes that soil at Ijero-Ekiti mine site were slightly acidic soil $\mathrm{pH}$, reduced organic carbon, total nitrogen, available phosphorus, exchangeable cations and averagely elevated heavy metal contents. Since most of the metals analyzed for were more or less within the permissible limit according to the guidelines of World Health Organization (WHO), that means the plant is considerably safe for human and animal consumption. The reason for this safety may be due to the manual technologies adopted at the Ijero-Ekiti mine sites as compared to other sites such as: Awo and Itagunmodi where mechanized technologies were used, thereby resulting to greater discharge and accumulation of this respective metals causing more damage and degradation to the plants and soil. The study underscores the need for strict mining operation policies in Nigeria with quick remediation strategies to restore degraded soil and plant life.

Consent for publication: All authors are aware of the publication of this manuscript.

Availability of data and material: The datasets used and/or analysed during the current study are available from the corresponding author on request.

Competing interest: The authors declare that they have no competing interest.

Funding: The research was self-funded.

Authors' contributions: Mr. E. S. Abiya designed the experiment, Ekpo Wisdom carried out the laboratory works. Dr. F. A. Ologundudu carried out the statistical analysis and interpretation of the results. The author(s) read and approved the final manuscript.

Acknowledgement: The researchers want to appreciate the Technical Staff of the Department of Biology, Federal University of Technology, Akure, Nigeria.

\section{REFERENCES}

Adegboye MA (2012) Effect of mining on farming in Jos South Local Government Area of Plateau State. J. Soil Sci. Environ. Manage. 3:77-83. DOI: 10.5897/JSSEM11.048

Adekoya JA, Kehinde-Phillips O, Odukoya AM (2003) Geological distribution of mineral resources in Southwestern Nigeria. In: Elueze A.A. (ed.) Prospects for Investment in Mineral Resources of Southwestern Nigeria. Nig. Mining and Geosci. Soc. (NMGS), 1- 13.

Akcil A, Koldas S (2006) Acid Mine Drainage (AMD) Causes, Treatment and case Studies. Journal of cleaner Production, 14 , 1139-1145. 
Arogunjo A (2007) Heavy metal composition of some solid minerals in Nigeria and their health implications to the environment. Journal of Biological Sciences 10(24):4438-43 DOI: $10.3923 /$ jbs.2007.4438.4443.

Facchinelli, A., Scchi, E., \& Mallen, L. (2001). Multivariate statistical and GIS-based approach to identify heavy metal sources in soils. Environ. Pollution. 114, 313-324.

Katar S., (2009). Environmental Degradation and Measures for Its Mitigation with Special Reference to India's Agricultural Sector. India. Journal of Agriculture. Econ. 64, 1, Jan.-March

Keskin, K. \& Makineci, E. (2009). Some soil properties on coal mine spoils reclaimed with black locust (Robinia pseudoacacia L.) and umbrella pine (Pinuspinea L.) in AgacliIstanbul, Environ. Monit. Assess., 159, 407-414.

Lockitch G (1993). Perspective on lead toxicity. Cline. Biochem., 26: 371-381.

Marcovecchio J.E., Botte S.E., \& Freije R.H. (2007). Heavy Metals, Major Metals, Trace Elements. In: Handbook of Water Analysis. L.M. Nollet, (Ed.). 2nd Edn. London: CRC Press; 275-311.
Martinez, C.E. \& H.L. Motto, 2000. Solubility of lead, zinc and copper added to mineral soils. Environmental Pollution.107: 153-158.

Myśliwa-Kurdziel B., Prasad M.N.V., \& Strzałka, K., (2004). Photosynthesis in heavy metal stressed plants. In: Prasad MNV (ed) Heavy metal stress in plants: from biomolecules to ecosystems. Springer, Berlin, 146-181.

Olafisoye O. B., Tejumade A. \& Otolorin A. O., (2013). Heavy Metals Contamination of Water, Soil, and Plants around an Electronic Waste Dumpsite. Pol. J. Environ. Stud., 22(5): 14311439.

Suzan H. H. Oelofse (2008) Protecting a Vulnerable Groundwater Resource from the Impacts of Waste Disposal: A South African Waste Governance Perspective, International Journal of Water Resources Development, 24:3, 477-489.

Tembo D.B., Sichilongo K, \& Cernak J., (2006). Distribution of copper, lead, cadmium and zinc concentrations in soils around Kabwe Town in Zambia. Chemosphere, 63: 497-501.

Yang M.G., Lin, X.Y., \& Yang X.E (1998). Impact of Cd on growth and nutrient accumulation of different plant species. China Journal of Applied Ecology, 19:89-94. 